\title{
$\mathrm{LBP}$ 감광드럼의 표면전위 특성에 관한 연구
}

\author{
조현섭 ${ }^{1}$, 유인호 $2^{*}$ \\ ${ }^{1}$ 청운대학교 전자공학과, ${ }^{2}$ 전북대학교 IT응용시스템공학과
}

\section{A Study on the Characteristics for Surface Potential of Photoconductive Drum in LBP}

\author{
Hyun-Seob Cho ${ }^{1}$ and In-Ho $\mathrm{Ryu}^{2^{*}}$ \\ ${ }^{1}$ Dept. of Digital Broadcasting \& Electronic Engineering, Chungwoon Univ., \\ ${ }^{2}$ Dept. of IT Applied System Engineering, Chonbuk National University
}

요 약 LBP 현상기 롤러는 시간이 지나면 자기력과 자화 특성이 감소하게 되며 이런 자성체 감소로 인해 인쇄 품 질이 떨어진다. 본 연구에서는 재활용에 따른 현상기 롤러의 자성 분포를 조사하여 신제품과 비교함으로써 재활용의 사용 가능성 및 자성체의 경시 변화에 대해 제한하였다.

\begin{abstract}
Developer roller of LBP(laser beam printer) cartridge made with magnetic substance and density of magnetic flux was decreased with the elapse of a year. Owing to this reason, quality of printing was decreased with decreasing of magnetic flux. This study investigated about the elapse of a year of magnetic substance and possible about usage of recycling production.
\end{abstract}

Key Words : LBP(laser beam printer), Magnet Roller, Thermal Gravimetry Analyzer

\section{1. 서론}

일회용으로 제작되는 LBP(laser beam printer) 카드리 지는 일부 핵심부품인 드럼, 현상기 롤러, 대전 유닛 및 클리닉 유닛외에는 수차례 재활용이 가능한데도 폐기되 는 현실을 감안하여 카드리지를 일부 수거해 재생산 의 뢰 후 충분한 테스트 과정을 거쳐 재활용 여부를 판단하 는 기준과 정확한 실험이 이루어지지 않는 실정이다[1,2]. 최근에는 일부 핵심 부품 중 현상기 롤러를 제외하고는 국산화 개발이 가능하게 되었으며 $\mathrm{LBP}$ 의 국산화 수준도 $20 \%$ 에 이르고 있다. 만일 현상기 롤러를 신품으로 교체 한다면 재활용의 의미는 없어지며 LBP 카드리지를 신품 으로 구입하는 것이 더 효과적일 것이다. 따라서 $100 \%$ 수 입에 의존하고 있는 LBP 카드리지의 현상기 롤러를 재활 용함으로써 대폭적인 경비절감은 물론 국가적으로는 수 입대체 효과 뿐 만 아니라 국산화 개발 수준도 $50 \%$ 까지 향상시킬 수 있을 것으로 기대하고 있다[3]. 특히 현상기
롤러는 자성체로 만들어 졌기 때문에 토너의 자기적 특 성과 상관관계를 갖게 되는데 재활용 후 이러한 상관관 계를 규명하고 기초 연구데이터로 만들어놓은 자료가 없 어 재활용에 따른 자성 성질 변화에 대한 기초 자료가 필 요한 실정이다. 또한 LBP 카드리지가 완전히 분해되는데 는 100 년의 기간이 필요하기 때문에 환경오염에 심각한 문제가 대두됨에 따라 환경 보호대책으로도 현상기 롤러 의 재활용 연구는 시급한 상황이다[4,5]. 일반적으로 사용 하고 있는 LBP 카드리지의 규격품은 현재 약 30 여개가 존재하고 있지만, 그중 $\mathrm{BX}$ 와 XP8/16는 인쇄 매수가 10,000 매 이지만 현상기 롤러를 제외한 일부 핵심부품을 재활용함으로써 30,000 매 까지 인쇄 가능하며 만일 현상 기 롤러가 재활용되면 그 인쇄 매수는 상당에 이르게 될 것으로 기대된다.

따라서 LBP 카드리지중 BX와 XP8/16 현상기 롤러는 자성체로 이루어졌으므로 자성체가 경시변화가 일어나듯 이 사용함에 따라 자속밀도가 감소하게 되는데 자속 밀

*교신저자 : 유인호(toto00@chonbuk.ac.kr) 
도가 감소하게 되면 토너의 흡착량이 적어지면서 인쇄는 흐려지게 된다.

\section{2. 연구 수행 방법 및 결과}

\section{1 현상기 롤러의 자기적 특성 분석}

현상기 롤러의 자기적 특성 분석을 위하여 현재 일반 적으로 사용하고 있는 규격품 30 여개 중 $\mathrm{BX}$ 와 XP 8/16 (일명 1663) LBP 카드리지의 현상기 롤러에 대해 정품과 재활용품 2개를 샘플로 채취하여 특성을 비교하였다.

Magnet 롤러의 자기적 특성 측정은 $\mathrm{BX}(18[\mathrm{~mm} \Phi] \times 305$ $[\mathrm{mmL}])$ 와 XP $8 / 16(14[\mathrm{~mm} \Phi] \times 305[\mathrm{mmL}])$ 를 길이 방향으로 3 등분(Left, Middle, Right Point)하여 둘레 $[\Phi]$ 방향으로 측 정하였고, 둘레방향으로 4 등분( $72,144,216,288$ )하여 길이[L]방향으로 각각 측정하였다 $[6,7,8]$.

그림 1-3은 $\mathrm{BX}$ 롤러의 정품과 재활용품에 대해 각 지 점에서 측정한 결과들 값이다. 측정한 결과에서 나타나듯 이 정품과 재활용품 모두 피크 값은 비슷하게 나타나고 있지만 정품보다 재활용품이 약간 피크 값이 나타나는 각도가 뒤쳐지는 현상이 나타났다.

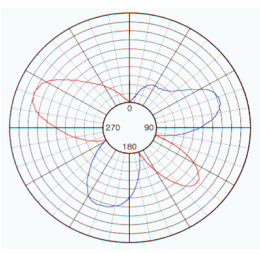

정 품

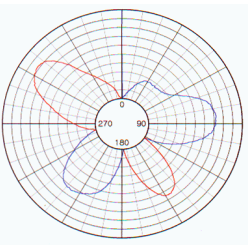

재활용품

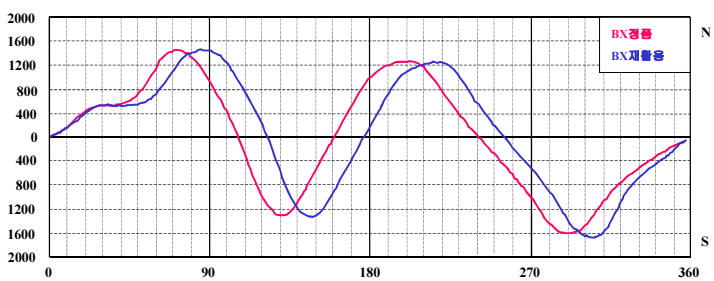

[그림 1] BX 롤러의 왼쪽지점 측정값

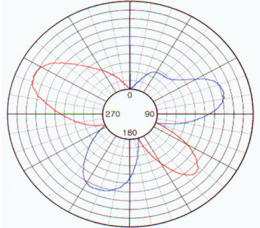

정 품

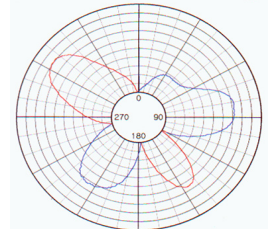

재활용품

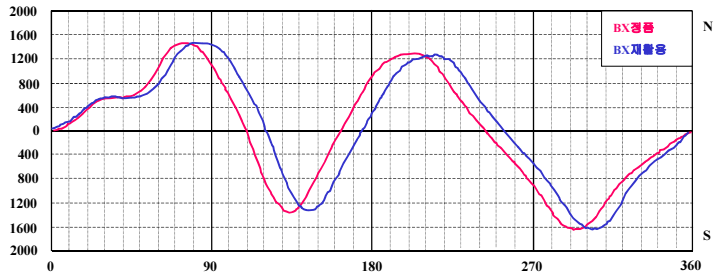

[그림 2] $\mathrm{BX}$ 롤러의 중앙지점 측정값
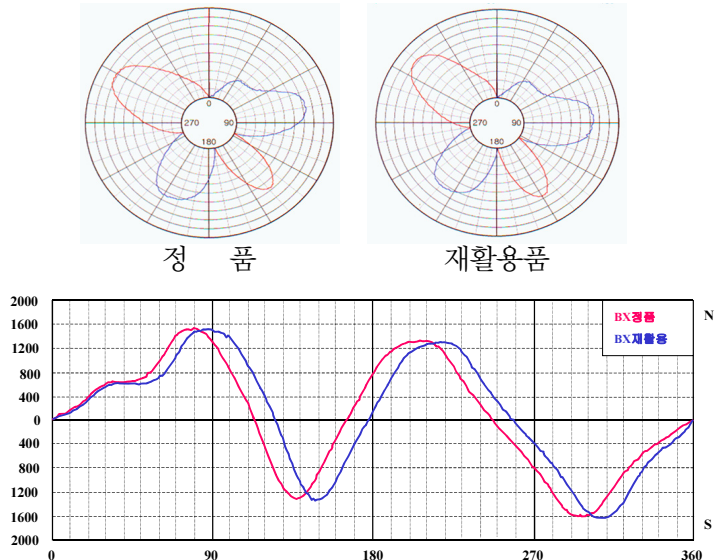

[그림 3] BX 롤러의 오른쪽지점 측정값

그림 4-6은 XP 8/16롤러의 정품과 재활용품에 대해 각 지점에서 측정한 결과들 값이다. $\mathrm{BX}$ 롤러와 마찬가지로 측정한 결과에서 나타나듯이 정품과 재활용품 모두 피크 값은 비슷하게 나타나고 있지만 정품보다 재활용품이 약 간 피크 값이 나타나는 각도가 뒤처지는 현상이 나타났 다. 이러한 현상은 롤러 측정 시 약간의 변형의 원인으로 작용한 것으로 본다.
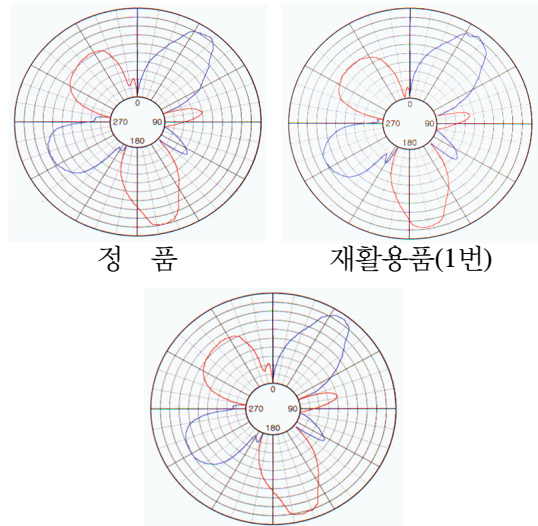

재활용품(2번) 


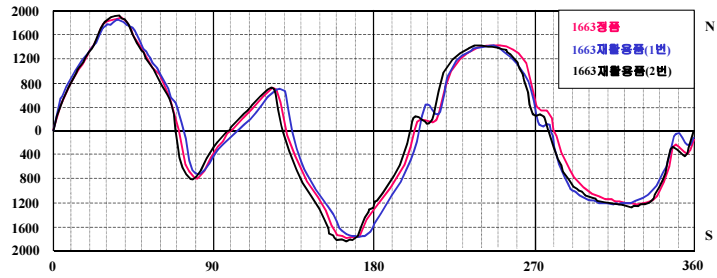

[그림 4] XP 8/16 롤러의 왼쪽지점 측정값
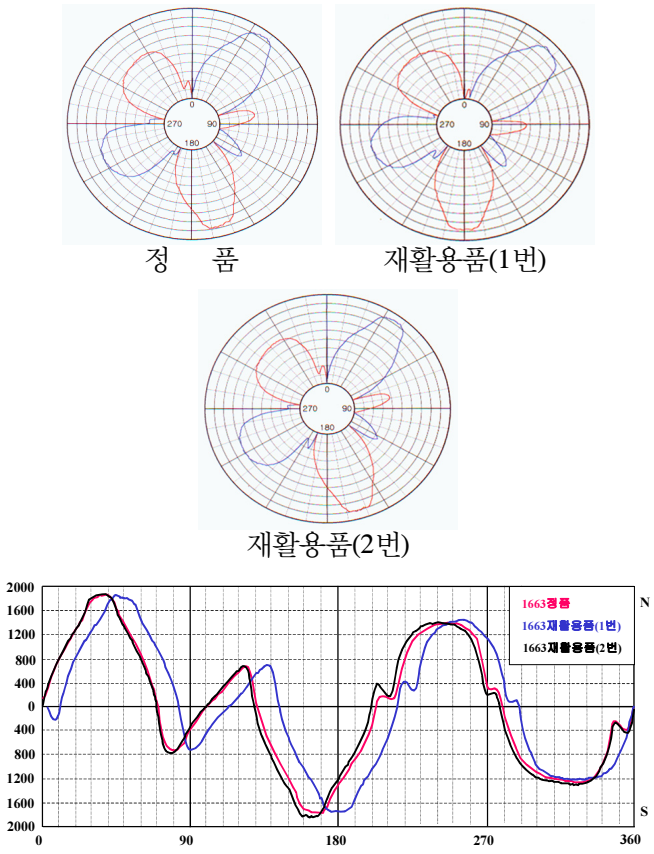

[그림 5] XP 8/16 롤러의 중앙지점 측정값

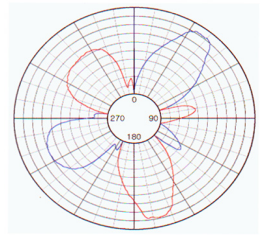

정 품

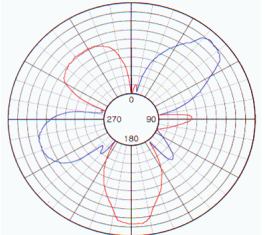

재활용품(1번)

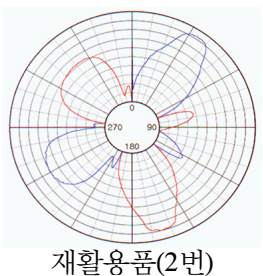

재활용품(2번)

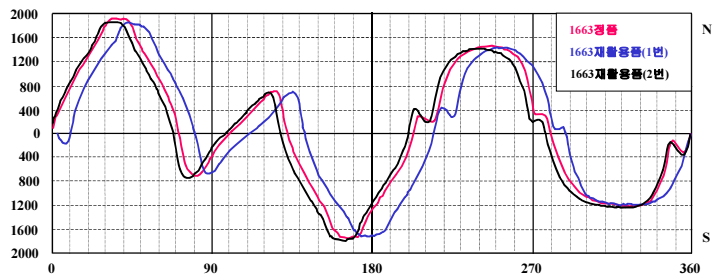

[그림 6] XP 8/16 롤러의 오른쪽지점 측정값

\section{2 현상기 토너의 특성 분석}

토너 파우더의 Magnetite $\left(\mathrm{Fe}_{3} \mathrm{O}_{4}\right)$ 의 분리 방법은 다음 과 같다.

Tolune : Toner(M+R) $(2: 1)$

Magnetic Stirring $3 \mathrm{hrs}$ 후 $24 \mathrm{hrs}$ 방치

$\downarrow$

Filtering(Filter Paper)

$\downarrow$

Xylene 세척(2회)

$\downarrow$

Trichloro Etylene 세척(2회)

$\mathrm{ClCH}: \mathrm{CCl}_{2}\left(\mathrm{C}_{2} \mathrm{HCl}_{3}\right)$

$\downarrow$

Acetone + Ethylene(1:) 3회 세척

$\left(\mathrm{CH}_{3} \mathrm{COCH}_{3}+\mathrm{C}_{2} \mathrm{H}_{5} \mathrm{OH}\right)$

$\downarrow$

Drying $60^{\circ} \mathrm{C}$ dry oven(open 상태)

Notice 폭발주의

$\downarrow$

Filter Paper상 Seperating Particle

$\downarrow$

Milling(유발로 응집된 분말 해쇄)

제조공정은 그림 7과 같다.

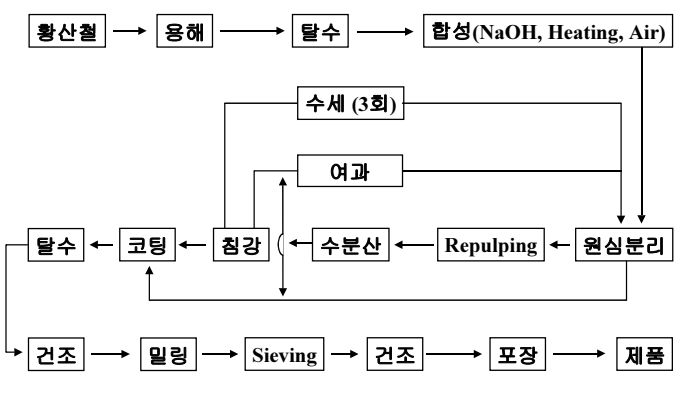

[그림 7] 제조공정 


\subsubsection{SEM(Scanning Electron Microscope)}

정품 토너는 대체적으로 동일한 입자를 나타내고 있지 만 재활용 토너는 아주 미세한 소립자가 분포되어 있고 불균일하게 나타났다.

또한 정품 토너는 Magnetite $\left(\mathrm{Fe}_{3} \mathrm{O}_{4}\right)$ 가 보편적으로 수 지하고 잘 혼합 분산되어 밀집되어 타원형 같지만 거의 구 형태로 나타나고 있지만, 재활용 토너에서는 Magnetite $\left(\mathrm{Fe}_{3} \mathrm{O}_{4}\right)$ 가 수지하고 친화력이 없고 분포가 균일 하지 못하며 구형태 과립이 잘 이루어지지 않았고, 수지 가 한쪽으로 몰려있는 형태로 나타났다.

이러한 원인은 분산이 잘 이루어지지 않았거나 수지가 적합하지 않거나 공정조건이 맞지 않기 때문이며, 정품 토너와 수지는 같지만 Magnetite $\left(\mathrm{Fe}_{3} \mathrm{O}_{4}\right)$ 가 틀리면 재활용 토너와 같은 현상이 나올 수 있다.

\subsubsection{TGA(Thermal Gravimetry Analyzer)}

정품 토너는 366.44 414.82[ $\left.{ }^{\circ} \mathrm{C}\right]$, 생성된 무게는 $-53.75[\% / \mathrm{min}]$ 이고, 수지 무게는 53.69[\%]로 나타났지만, 재활용 토너는 $349.82 \sim 413.59\left[{ }^{\circ} \mathrm{C}\right]$, 생성된 무게는 $-49.79[\% / \mathrm{min}]$ 이고, 수지 무게는 $49.75[\%]$ 로 나타났다. 이는 재활용 토너의 Magnetite $\left(\mathrm{Fe}_{3} \mathrm{O}_{4}\right)$ 가 다소 많게 나타 나기 때문으로 사료된다.

\subsubsection{EDS(Energy Dispersive Spectrometer)}

분석 결과 정품에서는 $\mathrm{Fe}, \mathrm{Si}, \mathrm{Ti}, \mathrm{Ca}, \mathrm{Cr}$ 과 $\mathrm{O}$ 가 각각 $64.941,2.756,0.494,0.177,0.127,31.505[\%$ Element]나 타났고, 재활용품에서는 망간이 제거되지 않아 $\mathrm{Fe}, \mathrm{Mn}$, $\mathrm{Si}, \mathrm{Ti}, \mathrm{Cr}$ 과 $\mathrm{O}$ 가 $65.784,0.333,2.303,0.210,0.164$, $31.206[\%$ Element]로 나타났다.

\subsubsection{TEM(Transmission Electron Microscope)}

정품 토너의 크리스탈 시스템은 정육면체 구조로 나타 났지만, 재활용 토너는 정육면체 이지만 소미립자가 분포 되어 나타났다. 정육면체는 각이 지기 때문에 수지와 잘 혼합되지 않은 이유도 있지만, 재활용 토너의 소미립자 분포는 합성를 일으켰기 때문으로 사료된다.

\subsubsection{VSM(Vibrating Sample Magnetometer)}

\subsubsection{1. 용해 전}

$\mathrm{Hc}[\mathrm{Oe}], \mathrm{Ms}[\mathrm{emu} / \mathrm{g}]$ 와 $\mathrm{Mr}[\mathrm{emu} / \mathrm{g}]$ 가 정품과 재활용품에 서 각각 $57.5,29.8,1.7$ 과 $80.7,32.2,2.2$ 로 나타났다.

\subsubsection{2. 용해 후}

$\mathrm{Hc}[\mathrm{Oe}], \mathrm{Ms}[\mathrm{emu} / \mathrm{g}]$ 와 $\mathrm{Mr}[\mathrm{emu} / \mathrm{g}]$ 가 정품과 재활용품에
서 각각 $87.6,48.6,4.1$ 과 $88.3,57.0,5.0$ 으로 나타났다. 표 1에서와 같이 수지와 Magnetite $\left(\mathrm{Fe}_{3} \mathrm{O}_{4}\right)$ 용해 분리후 의 자기적 특성은 모두 같은 반면에 용해 분리전의 자기 적 특성은 많은 차이가 나타나고 있으며, 분산이 잘 이루 어지지 않았거나 수지가 적합하지 않거나 공정조건이 맞 지 않기 때문으로 사료된다.

[五 1] Magnetic Roller

\begin{tabular}{|c|c|c|c||c|c|c|}
\hline \multirow{3}{*}{ 구 분 } & \multicolumn{5}{|c|}{ Peak (Gauss) } \\
\cline { 2 - 7 } & \multicolumn{3}{|c||}{ N극 } & \multicolumn{3}{c|}{ S극 } \\
\cline { 2 - 7 } & Max & Min & Ave & Max & Min & Ave \\
\hline XP8/16 & 1875.0 & 1406.3 & 1640.6 & 1806.6 & 732.4 & 1269.5 \\
\hline BX & 1103.5 & 957.0 & 1030.25 & 1230.5 & 996.1 & 1113.3 \\
\hline \hline \multirow{2}{*}{ 구분 } & \multicolumn{3}{|c||}{ Interval[deg } & \multicolumn{4}{c|}{ Total Area } \\
\cline { 2 - 7 } & Max. & Min. & Ave. & N극 & S극 & N+S극 \\
\hline XP8/16 & 102.0 & 30.0 & 72.0 & 159296.9 & 162802.7 & 322099.6 \\
\hline BX & 114.0 & 53.0 & 90 & 109423.8 & 101191.4 & 210615.2 \\
\hline
\end{tabular}

\section{3. 결론}

본 연구에서는 재활용에 따른 현상기 롤러의 자성 분 포를 조사하여 신제품과 비교함으로서 재활용의 사용가 능성 및 자성체의 경시변화에 대해 제안하였다. 복사기, $\mathrm{LBP}$, 보통용지팩스( $\mathrm{PPF})$, 디지털복사기 토너는 주로 Magnetite $\left(\mathrm{Fe}_{3} \mathrm{O}_{4}\right)$ 와 Ferrite $\left(\mathrm{Fe}_{2} \mathrm{O}_{3}\right)$ 성분계가 대부분이며 LBP 현상기 롤러의 재활용을 위해서는 토너의 Magnetite 는 $\mathrm{Hc}: 90 \sim 95[\mathrm{Oe}], \mathrm{Ms}: 80 \sim 85[\mathrm{emu} / \mathrm{g}], \mathrm{Mr}: 9 \sim$ $10[\mathrm{emu} / \mathrm{g}]$, particle size : $0.22[\mu \mathrm{m}]$, 비표면적 : 4 $6\left[\mathrm{~m}^{2} / \mathrm{g}\right]$, Magnetite 함량 : $48 \sim 50[\%]$, 흑색도(I.D) : 1.42 의 특성과 Magnetite $\left(\mathrm{Fe}_{3} \mathrm{O}_{4}\right)$ 40 45\%와 수지(Resin) 55 $60 \%$ 혼합하여 제조되어야 한다.

\section{참고문헌}

[1] 미래 공학도를 위한 재료과학, 교보문고, 2006, 8, 초 판 4 쇄

[2] 방전·고전압공학, 동명사, 1991, 3

[3] 전극계측기초, 동일출판사, 1995,2

[4] C. A. Smith and A. B. Corripio, principles and practice of automatic process control, Wiley-Interscience, 2002.

[5] C. D. Johnson, "Disturbance-accomodating control; an overview", proc. ACC, pp. 526-536, 2004. 
[6] Howard Kaufman, Izhak Bar-Kana and Kenneth Sobel, "Direct Adaptive Control Algorithms," Springer-Verlag, 1999

[7] B. C. Kuo, Automatic Control Systems, Prentice-Hall, 1991

[8] Robert H. Bishop, Modern Control System Anylysis and Design Using MATLAB, Addison-Wesley Publishing Company

\section{조 현 섭(Hyun-Seob Cho)}

[종신회원]

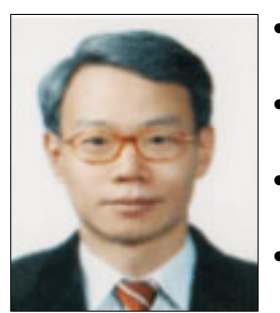

- 1990년 2월 : 원광대학교 공과대 학 전기공학과 졸업

- 1992년 2월 : 원광대학교 공과대 학 전기공학과(석사)

- 1996년 2월 : 원광대학교 공과대 학 전기공학과(박사)

- 1996년 1월 1997년 6월 :

Department of Electrical and Computer Engineering, University of California Irvine(UCI) 연구원

- 1998년 1월 현재 : 한국전력기술인협회 고급감리원 (전력감리)

- 1997년 3월 현재 : 청운대학교 부교수

<관심분야>

전기공학, 공장자동화, 응용전자

유 인 호(In-Ho Ryu)

[정회원]

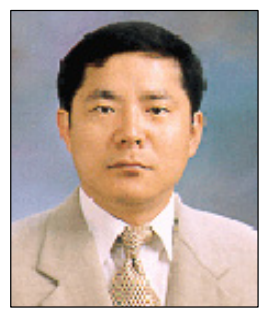

- 1984년 2월 : 원광대학교 전기공 학과 공학사

- 1986년 2월 : 건국대학교 전기공 학과 공학석사

- 1999년 2월 : 원광대학교 전기공 학과 공학박사

- 1993년 3월 현재 : 전북대학 교 IT응용시스템공학과 교수

<관심분야>

자동제어, 멀티미디어 시스템, PLC시스템 제어 